\title{
Fernanda
}

Guimarães Goulart ${ }^{1}$

\section{Costurando \\ conversas de \\ varanda: \\ expressões \\ ornamentais, subjetivas \\ e memoriais \\ em fachadas e palavras \\ da cidade de papel}

Sewing balcony conversations:

ornamental, subjective and memorial expressions on facades and words of the paper city.

Costurando conversaciones de balcones: expresiones ornamentales, subjetivas y memoriales en fachadas y palabras de la ciudad de papel. 


\title{
Resumo
}

Este artigo toma como alicerce o projeto "Urbano Ornamento: um inventário de grades ornamentais em Belo Horizonte (e outras belezas)", que resultou na tese de doutorado da autora e em livro homônimo, e que tem como produto um exaustivo inventário de desenhos vetoriais que reproduzem modelos da serralheria artística integrada à arquitetura na capital mineira. $O$ objetivo é circunscrever como objeto de análise as recorrentes tipologias arquitetônicas encontradas no trabalho de campo, nomeadas aqui de casas patchwork. Essas moradias que conjugam azulejos e grades ornamentais em suas fachadas, bem como as entrevistas que realizamos com seus moradores são, aqui, um pretexto para refletir sobre a sobrevivência do ornamento no espaço urbano atual, tomando como base sua dimensão popular, as narrativas urbanas e a relação entre imaginação e memória..

Palavras-chave: ornamento, artes gráficas, arquitetura, memória, narrativa.

\begin{abstract}
This article is based on the project "Urban ornament: an inventory of ornamental grids in Belo Horizonte (and other beauties)", which resulted in the author's doctoral thesis and in a book with the same name, which has as its outcome an exhaustive inventory of vector drawings that reproduce models of artistic metalwork integrated with architecture in the capital of Minas Gerais/ Brazil. The objective is to circumscribe, as an object of analysis, the recurring architectural typologies found in the fieldwork, named here patchwork houses. These houses that combine tiles and ornamental grids on their façades, as well as the interviews we conducted with their residents are, here, a pretext to reflect about the survival of the ornament in the current urban space, based on its popular dimension, the urban narratives and the relationship between imagination and memory.
\end{abstract}

Keywords: ornament, graphic arts, architecture, memory, narrative.

\section{Resumen}

Este artículo se basa en el proyecto "Urbano Ornamento: un inventario de rejas ornamentales en Belo Horizonte (y otras bellezas)", que resultó en la tesis doctoral de la autora y en un libro del mismo nombre, que tienen como producto un inventario exhaustivo de dibujos vectoriales que reproducen modelos de rejería artística integrados con la arquitectura en la capital de Minas Gerais/Brasil. El objetivo es circunscribir las tipologías arquitectónicas recurrentes que se encuentraran en el trabajo de campo de investigación, denominado aquí como casas patchwork. Estas casas que combinan azujelos y rejas ornamentales en sus fachadas, así como las entrevistas que realizamos con sus residentes son, aquí, un pretexto para reflexionar sobre la supervivencia del adorno en el espacio urbano actual, basado en su dimensión popular, las narrativas urbanas y la relación entre imaginación y memoria.

Palabras-claves: ornamento, artes gráficas, arquitectura, memoria, narrativa.

\footnotetext{
1 Artista, designer e professora Adjunta do Departamento de Desenho da Escola de Belas Artes da Universidade Federal de Minas Gerais. E-mail: nandagg@ uol.com.br

LATTES: http://lattes.cnpq.br/3368536090111262

ORCID: https://orcid.org/0000-0002-0661-3022

ISSN: $2175-2346$
} 


\section{INSISTIR}

Lembro-me da história da "trepadeira insistente", fruto de uma conversa e de uma casualidade, na casa de Ivone, no bairro de Santa Tereza. Reparei, ao sair de sua cozinha e entrar no quintal, que havia uma trepadeira se esparramando sobre a estrutura de um toldo que se situava do lado esquerdo da porta da cozinha, cuja lona, deteriorada pelo tempo, existia apenas parcialmente. Perguntei sobre a útil e casual ocorrência, uma trepadeira florida preenchendo o espaço que faltava, criando uma sombra natural, um caramanchão improvisado, em meio ao concreto das paredes e do chão da área de serviço. Reparei que não havia nenhuma terra ali, apenas do outro lado da porta da cozinha, num estreito jardim cercado por uma mureta de cimento. Como esta trepadeira crescera ali, e de modo tão vigoroso, sem uma base de terra que a nutrisse?

Ivone apontou-me o lugar por onde escorria o robusto tronco retorcido da trepadeira: uma calha de chuva, descolada da parede pela força da planta que pedia passagem. Mostrou-me que ela nascera no chão de cimento, e até pouco tempo preenchera discretamente o espaço entre a parede e a calha, até que não se conteve, não coube atrás. E saiu atropelando tudo, alumínio, camadas de tinta, cimento, para que pudesse nutrir seus galhos frondosos que escorriam pelo falso caramanchão. Foi quando me contou que a trepadeira era de outros tempos e de outro lado do quintal, e preenchia um caramanchão de verdade, que sombreava a entrada do antigo barracão dos fundos, demolido para dar espaço ao novo espaço gourmet. Situava-se a mais ou menos uns doze metros do toldo atual, distância que o estreito jardim, hoje contornado pela mureta de concreto, preenchia, interrompido pela porta, que dava passagem da cozinha ao quintal. Disse que foram várias as tentativas de acabar com ela, após terem desmanchado o barracão. A planta insistia em crescer junto com as roseiras, até resolver cumprir seu destino longe dos olhos delas; saindo pela primeira fresta de luz, o intervalo entre a parede e o chão, provavelmente fruto da constante umidade vinda da calha; por fim incrustando-se na parede, subindo escondida, até poder vislumbrar o céu, onde encontrou o toldo. Fiquei imaginando se, há tempos, a velha trepadeira não deveria almejar um novo caramanchão.

- Será que posso dizer que o passado é alicerce, e a memória, ornamento? 


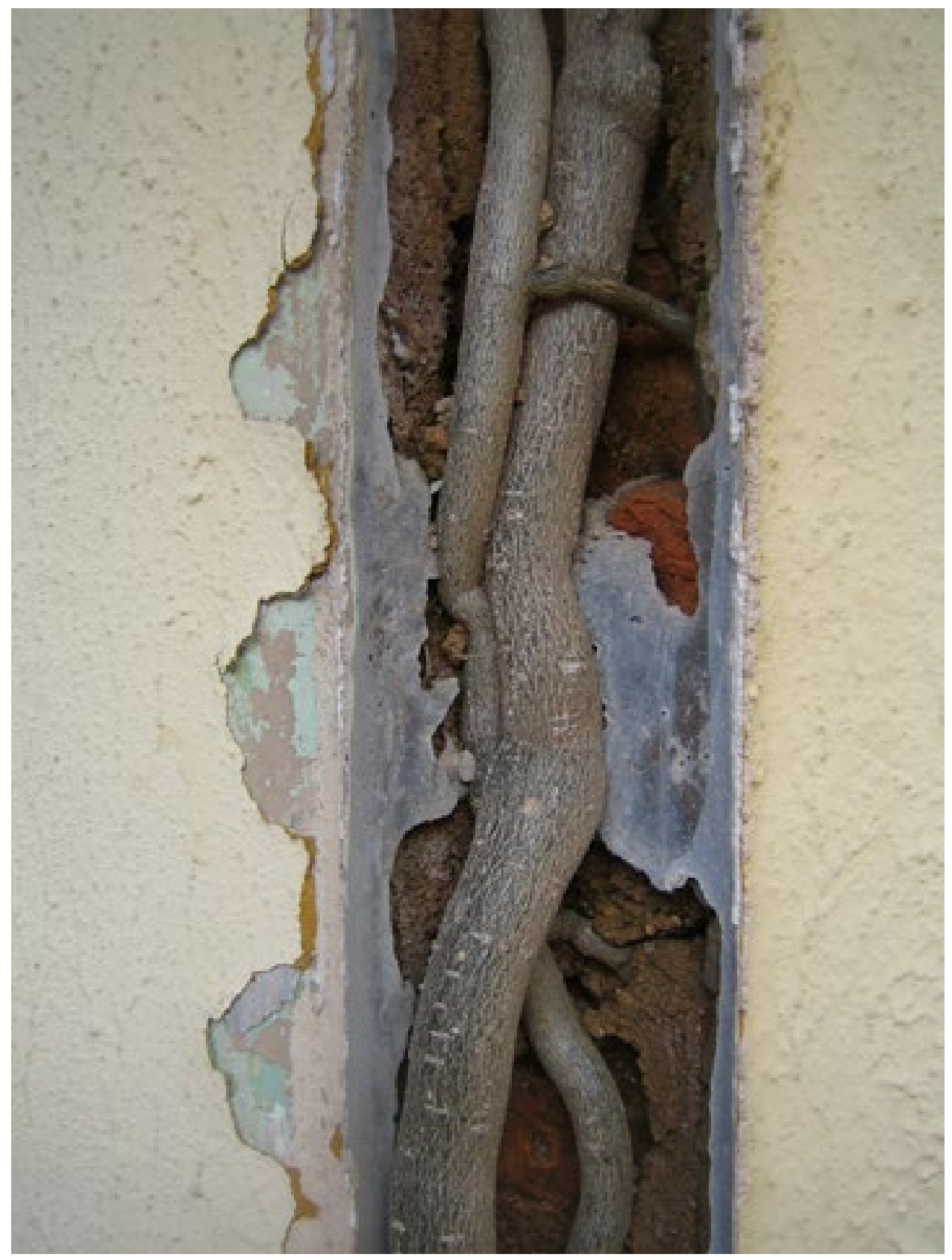

Fig. 1: A trepadeira insistente. Foto Fernanda Goulart.

\section{Inventário-alicerce}

Tendo como amplo norte a presença do ornamento no espaço urbano, o projeto "Urbano Ornamento: um inventário de grades ornamentais em Belo Horizonte (e outras belezas)" resultou em minha tese de doutorado e em livro homônimo, e pretendeu lançar um olhar interdisciplinar para as grades ornamentais na cidade de Belo Horizonte, aproximando os campos de saber da Arquitetura e das Artes Gráficas, não apenas pela evidente força gráfica que caracteriza esses bens integrados, mas também por outras interfaces - etnográfica, histórico-crítica, poético-ficcionais que thes possibilitassem comunicar. Adotei, como ponto de partida, a documentação fotográfica de cerca de 4000 fachadas de casas situadas em 34 bairros mais antigos 
da cidade e, cumprida essa etapa, procedi com a digitalização dos modelos encontrados, disponibilizando os cerca de 3000 desenhos vetoriais gráficos resultantes em arquivos abertos, editáveis. A ideia foi revisitar os antigos catálogos de ornamentos e criar uma versão atual - um tipo de edição, aliás, bastante usual nos dias de hoje, capaz de doar à cultura material imagens históricas - que pudesse abrigar um diálogo entre os diversos saberes convocados pelos ornamentos, não apenas sobre o bem arquitetônico integrado per se. Tal inventário é detentor de uma memória patrimonial - através da reconstituição de uma espécie de paisagem formal, capaz de guardar e lançar essas formas ao domínio público da criação, ou seja, devolvê-las à cidade - e outra mais livre, a partir das reflexões que os saberes, que nele tangenciam, possam suscitar.
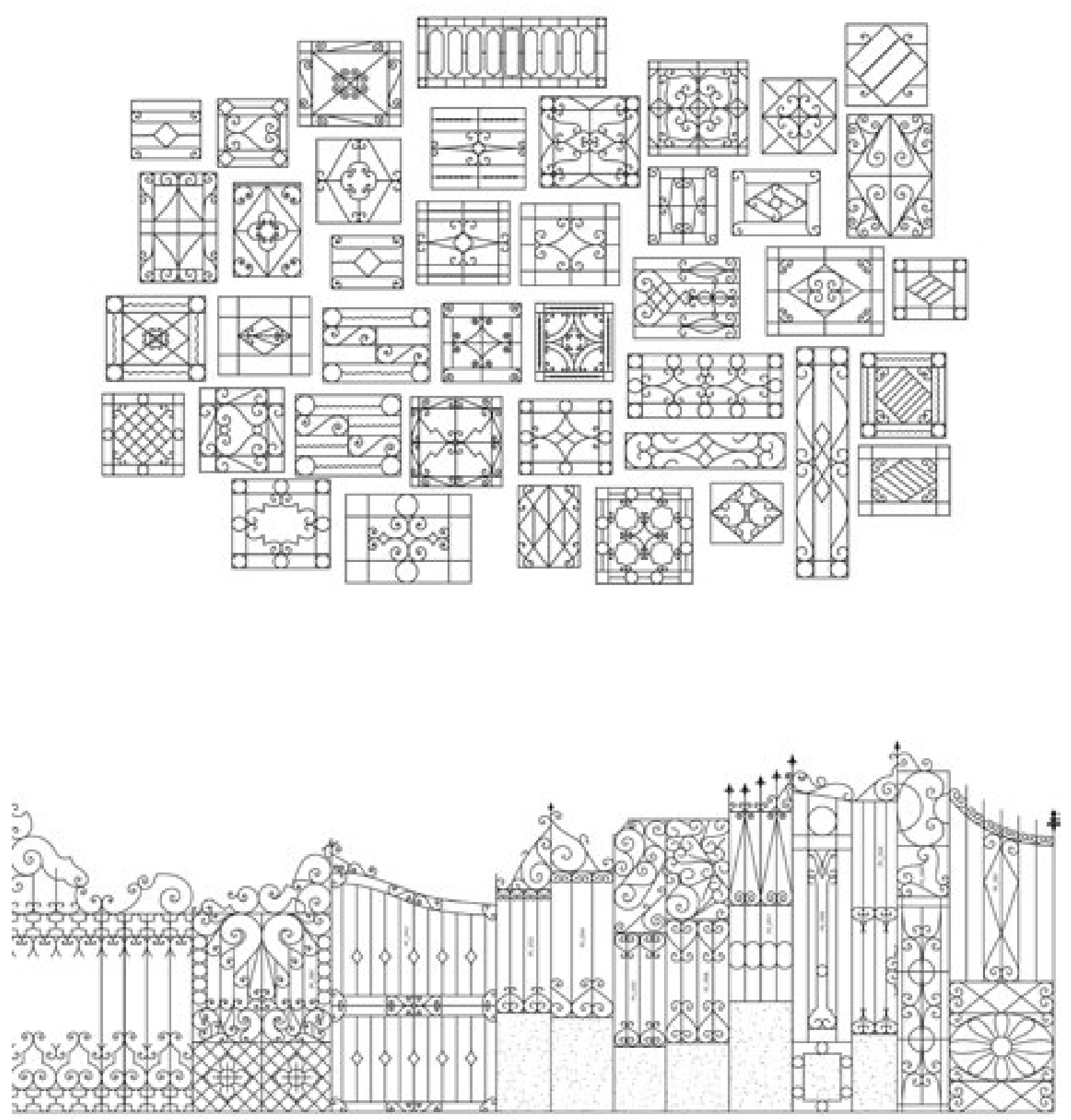


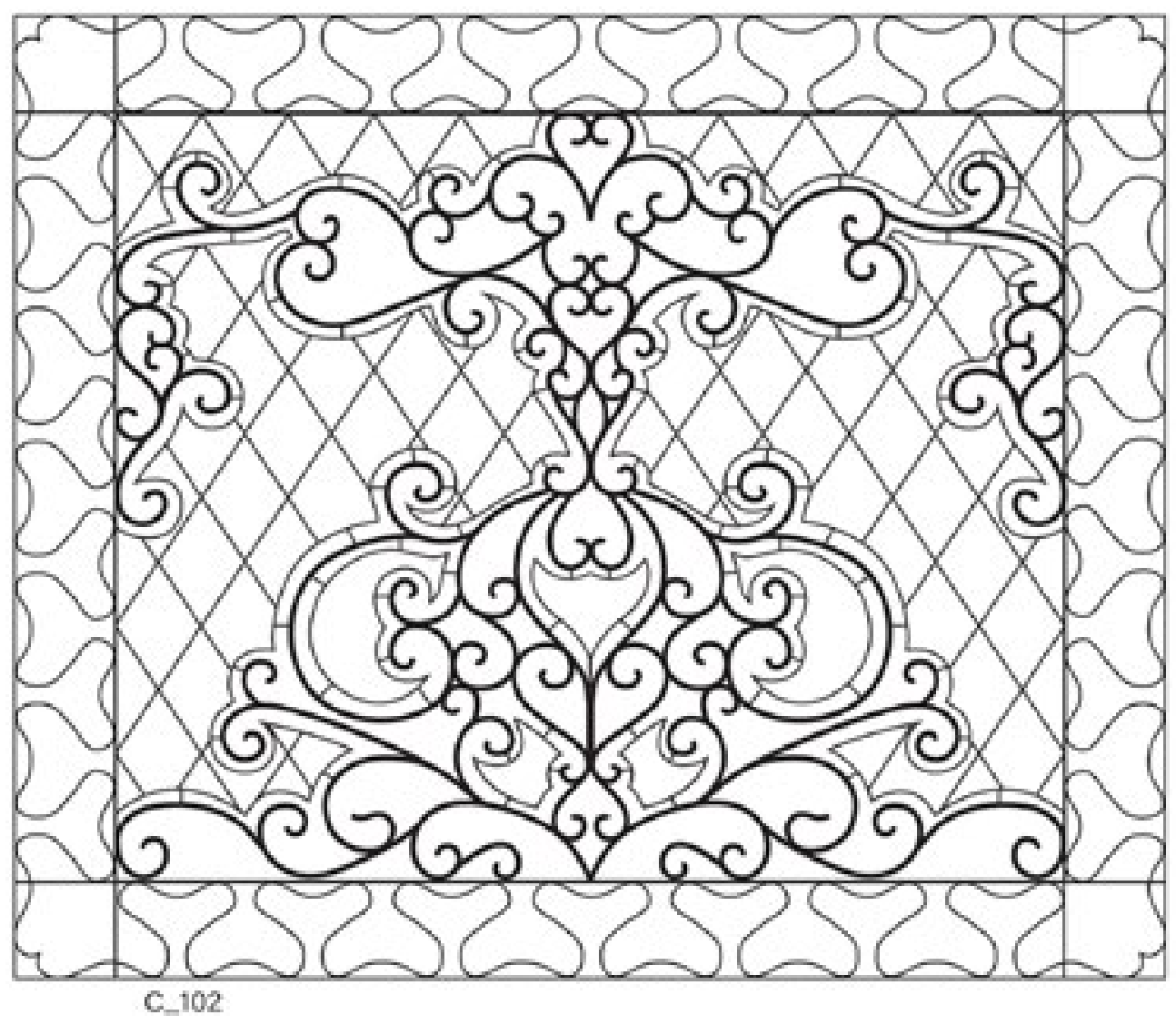

Fig. 2A, 2B e 2C: vetores do inventário Urbano Ornamento.

Se o objeto é a grade, seu lugar é a fronteira, e é na fachada que, nesta pesquisa, eles se revelaram. Nas fachadas as discussões sobre o ornamento ganharam sentido renovado, pelo modo como promovem encontros entre "presentes novos e antigos" na paisagem urbana. Um interior se revela através da fachada, a partir da qual não me interessei, a princípio, em adentrar. E que língua falam essas grades e fachadas? Como são capazes de exteriorizar domesticidades? Que histórias elas nos contam, sobre as cidades, as casas e o habitar dos homens? A hipótese inicial foi a de que as fachadas dessas casas, se tomadas como o limite entre os espaços urbano e doméstico, pudessem ser vistas como expressão pública da relação entre as pessoas e seu espaço de morada, por meio de práticas ornamentais que vão além da instalação das grades. Grade como pretexto, ornamento como condição. Não apenas em Belo Horizonte, mas em inumeráveis outras cidades no Brasil, há ainda uma familiar desobediência, mesmo que marcada pelo desconhecimento, dos preceitos estéticos da Arquitetura, materializada muitas vezes pelo que se costuma chamar de arquitetura sem arquitetos. Motivou-me pensar que tais deslocamentos são capazes de preservar a esfera autônoma do afeto, por dar lugar a apropriações criativas por parte dos moradores, os que fazem de suas fachadas uma espécie de assemblage ornamental, soprepondo elementos de naturezas ou formas diversas, combinando grades de modelos diferentes, com azulejos decorados, cobogós, tijolos aparentes, adesivos coloridos, pedras, pastilhas etc. Seria uma devolução do ornamento à sua dimensão prioritariamente primitiva e popular? Sobreposição não só de elementos mas também de tempos e 
modos de viver e habitar. Outras belezas...

O principal desafio do Urbano Ornamento foi criar uma metodologia híbrida e inventiva que contemplasse a abrangência das interfaces suscitadas por esse objeto, física e simbolicamente fronteiriço. Em vez de muros, busquei cercar a teoria com grades, aproveitando-me da transparência de sua sobreposição e da erótica de seus desenhos ornamentais. Significou tirar proveito das potencialidades metafóricas do objeto e, ornamentar o texto com sua transparência rendada. O inventário de desenhos é produto - de arquitetura, de design, de preservação do patrimônio material e imaterial, de mobilização da comunidade de apaixonados por grades ornamentais, não necessariamente artistas, arquitetos e designers. O inventário é produto mas também é convite. Criadora não das formas mas das paisagens onde elas se organizam, minha formação de artista teve papel fundamental. A esfera da arte, portanto, permeou a escritura, a forma de narrar, o desenvolvimento de estratégias metodológicas híbridas, criativas e livres para lidar com o objeto, conciliando lugares alternativos de pensamento, fala, escuta e morada.

\section{Amor Infiniti}

"O ornamento não vive por si só", afirma Carlos Del Negro (1961). Partamos do pressuposto de que a história do ornamento tenha começado no corpo - nas tatuagens da pele que o reveste e no pano que o cobre - para percebermos sua condição prioritariamente relacional: com seus componentes, suas aplicações, seu invólucro. Dos papéis às paredes, dos projetos às materialidades, da superfície ao revestimento necessário, é difícil pensá-lo e sistematizá-lo isoladamente, não apenas porque sua materialidade e função estão predominantemente determinados por arquiteturas e objetos, mas também porque ele estará, sempre, acompanhado de outro algo, para além da estética: suas implicações econômicas, políticas, sociais, morais, psicológicas, afetivas. Criar parâmetros para refletir sobre essa produção, dada a sua diversidade (de saberes, suportes, linguagens e técnicas), é um grande desafio, até porque há também outras histórias: paralelas, complementares, não-oficiais, marginais, aparentemente triviais, escondidas. Tais histórias, contadas por imagens, multiplicaram-se ao longo da existência humana e ao ritmo de sua vontade construtiva, de seu habitar e seu relacionar - com os homens e com as coisas - no mundo.

"O problema do ornamento não preocupa apenas os que se dedicam às artes pictóricas, ele interessa a todos que olham de modo crítico o mundo em que vivem", sugere René Smeets (1982). Tais implicações, que permeiam, sobretudo, sua história tardia, no final do século XIX, encarnaram posturas quase sempre apaixonadas e, muitas vezes, retiraram o ornamento de seu lugar aparentemente secundário para, a partir de sua natureza aderente, superficial, ressituá-lo no centro do debate. $\mathrm{Na}$ passagem do ecletismo ao modernismo, o advento da indústria, o progresso e o crescimento das cidades despiram o "recobrir" de seu lugar aconchegante na escrita dessa história. "Avessos às palavras", os ornamentos eram, simples e sensivelmente, "acréscimos de beleza" (PAIM, 2000, p. 9), conforto que chega ao fim com o debate moderno. A radicalidade tipicamente moderna retirou o ornamento da pauta dos debates (e da produção arquitetônica), e, em meados do século XX, aparentemente, 
a questão já havia sido dada como resolvida. Historicizá-lo, ou fazer dele algo ligado ao passado, teria sido a vitória moderna, não fosse, contudo, sua permanência inevitável e sua extinção impensável. Se muitas dessas questões já conhecemos, é ainda conveniente lembrar o que Paim nos adverte, que devemos tomar cuidado com as "fórmulas antiornamentais modernistas", para não evitarmos a riqueza do debate que se instala. Cuidar para não fazer do ornamento o problema exclusivo da tradição que a vanguarda condena, sobretudo quando falamos não somente nele, mas nas estratégias que o homem cria não apenas para construir (casas e objetos), mas para habitar o mundo.
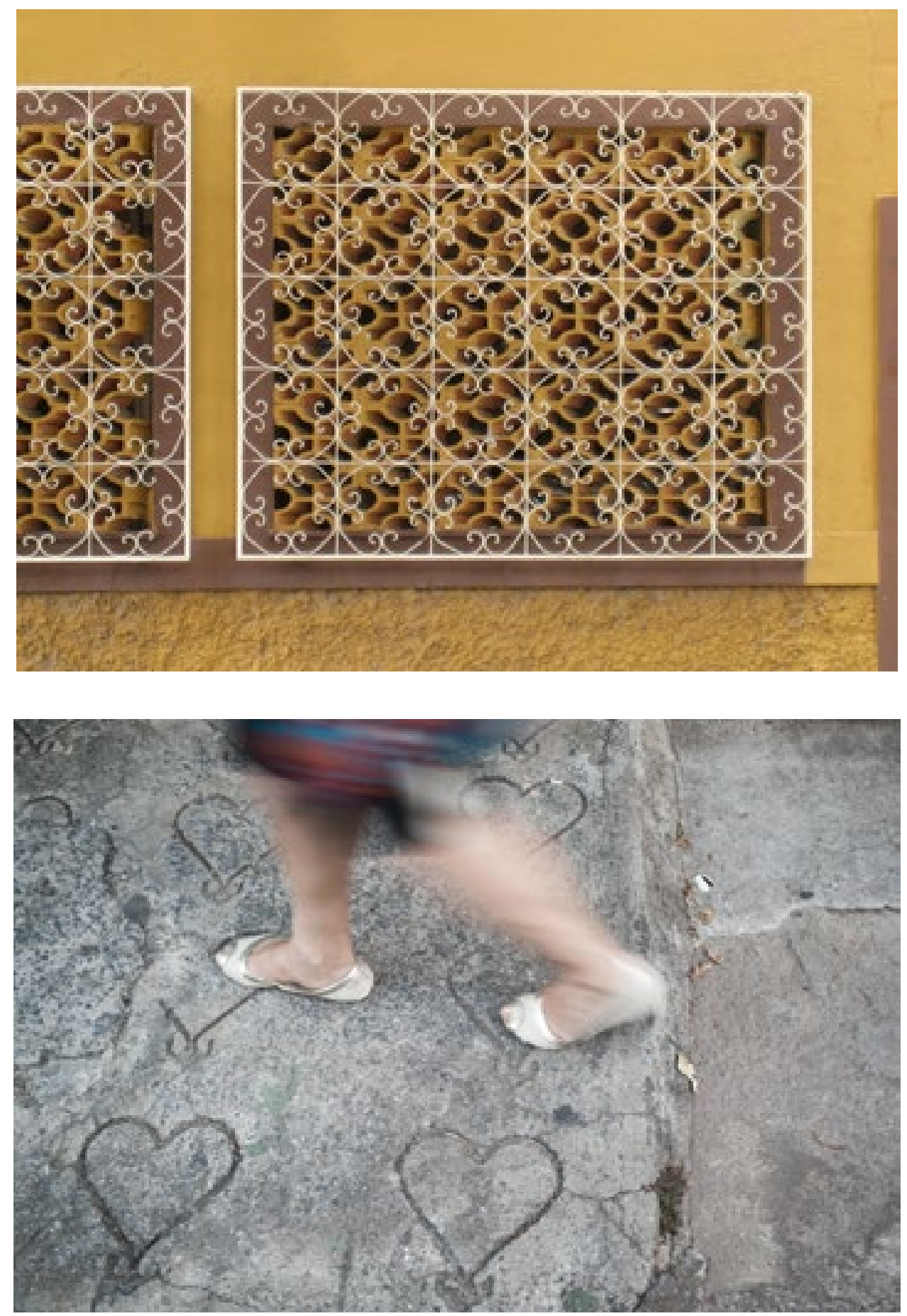

Fig. 3A e 3B. Grades e outras inventividades urbanas. Fotos: divulgação Urbano Ornamento. 
Ainda que não seja mais objeto de sentimentos extremos como a paixão, conforme sugere Paim, o ornamento seguramente permanece. A despeito do decoro urbano, ornamentar, em sua dimensão rotineira e proliferante, confunde-se, ainda, com um impulso trivial, doméstico, com uma ocupação despretensiosa do tempo. Relaciona-se não apenas com uma dimensão profissional ou teorizante - as artes aplicadas e seus agentes, os tratados e suas medidas -, mas também com preencher espaços vazios, decorar ao seu modo e, não necessariamente, ao modo do outro muitas vezes alheio à história oficial da Arte, da Arquitetura, do Ornamento. "Uma espécie de bem comum", atesta Carlos Del Negro (1961), ei-lo escancarado em sua dimensão prioritariamente primitiva e popular, para os quais talvez não haja prerrogativas contra o excesso, das tatuagens ao bolo de noiva, como explica Gombrich:

\begin{abstract}
...poucas civilizações estariam dispostas a negar que o valor interno deveria ser reconhecido mediante uma apropriada exibição externa. (...) Que eu saiba, nenhum membro contemporâneo da cultura criticou um templo hindu, um palácio mouro, uma catedral gótica ou uma igreja barroca espanhola como excessivamente ornamentada. O conceito não existia, pois nunca deve haver um excesso de amor e sacrifício invertidos no respeito e na veneração. A frase depreciativa 'parece um bolo de noiva' não foi registrada nas civilizações primitivas. (GOMBRICH, 2010, p. 17)
\end{abstract}

Substituir o princípio do horror vacui - impulso do decorador de preencher todos os espaços vazios - pelo do amor infiniti, propõe o autor, ciente de que o gesto de ornamentar, antes de decoro, pressupõe o afeto. Se o ornamento é, para Alberti, (paradoxalmente?) o avesso do luxo, onde não se coloca dinheiro, mas ordem, controle, economia formal, ele também possuirá um papel civilizador e pacificador. $\mathrm{Na}$ arquitetura, formas que não são apenas contemplação ou anestesia, mas que podem ser forma-força, se pedimos emprestada a terminologia de Paul Zumthor (2000), ou forma-experiência.

Um breve passeio pelas ruas nos revelará, além de grades, azulejos, cobogós e estuques, roupas floridas, acessórios e cores envolvendo corpos e gostos; grafites, stickers, tatuagens e outros palimpsestos; jardins, estátuas de jardins, samambaias e "namoradeiras" kitsch de cerâmica; fachadas ecléticas colorizadas, grades reutilizadas, releituras de um historicismo, espontâneas ou inconscientes. Cenário um pouco distante do "voltar-se para interior" pregado por Loos, como um gesto de dar as costas para a cidade - negar a "função clássica de comunicação estética e social que a fachada sempre teve" (HUCHET, 2005, 188) - ou para o passado, com seus muros brancos, e também os de Le Corbusier - para quem o conturbado tempo histórico impôs "pensar contra um fundo negro" (LE CORBUSIER, 1996, p. X).

\title{
Casas patchwork
}

Cumpridos os trajetos da pesquisa de campo em busca de grades, registrados e desenhados os ornamentos, alfinetadas as casas patchwork no mapa resultante, chegou o momento de sentarmo-nos à varanda para refletir sobre essas resistentes casinhas, na companhia de quem as habitava. Não se tratava de fazer outro estudo ri- 
goroso e, o que poderia ser um "estudo de caso", deu lugar a uma conversa livre, uma colcha de retalhos costurada a partir das falas dos moradores de um grupo de casas pertencentes ao inventário cujas fachadas têm em comum uma dupla manifestação ornamental, de grades e azulejos, que nomeei casas patchwork. Casinhas de retalho que encontramos nos caminhos que percorremos para buscar as grades, e que juntas poderiam formar uma colcha colorida, trabalhada e enredada nas tramas da cidade. Colcha abstrata, patchwork que só existiria em uma ou outra imaginação. Ou entre elas mesmas, numa conversa muda que suas superfícies ornamentadas porventura promovessem, rendadas, bordadas, costuradas, improvisadas. Por muito tempo, a minha curiosidade quis entrar em cada uma que vi, verificar se o "dentro" corresponderia ao cuidado do "fora", e quem eram aquelas pessoas que escolheram fazê- las assim, tão femininas aos nossos olhos. No entanto, por um tempo contentei-me em recebê-las enquanto superfície apenas, deixar que acontecessem como peças de uma coleção que, ao final, não seria minha. Até porque eu não queria despertar qualquer indiferença àquilo que em mim era pura pertença.

As nossas casas patchwork são autênticos exemplares de uma arquitetura feita não por arquitetos, mas por proprietários ou mestres de obras anônimos, como comprovado nas conversas com seus donos, na maioria idealizadores (ou parentes diretos deles). Casas construídas entre as décadas de 40 e 70 do século passado, grades e azulejos afixados predominantemente entre as décadas de 60 e 70, conjunção e moda modernas, tropicais e de certo modo kitsch, à maneira do referencial estudo de Dinah Guimaraens e Lauro Cavalcanti (2006). Essas casas, de acordo com os autores, desafiaram, ainda que não intencionalmente, a autoridade (e a caducidade) do pensamento funcionalista na arquitetura vigente, para povoar os bairros periféricos de outros sabores e efeitos estéticos - na interessante e convergente definição trazida por Guimaraens e Cavalcanti para o kitsch arquitetônico. A etimologia desse estrangeirismo remonta ao século XIX, época em que teria derivado, por corruptela, da palavra inglesa sketch, "quando turistas americanos, querendo adquirir uma obra de arte por um preço irrisório, pediam um esboço (sketch) da mesma" (GUIMARAENS \& CAVALCANTI, 2006, p. 25). Agregam-se a tal definição o sentido mais conhecido de imitação e fácil assimilação e, do alemão, as ideias de reformar os móveis para que pareçam mais antigos ou de "atravancar". Se, no passado, a gradação social era diretamente proporcional à ornamental, aqui há uma inversão, atestando o caráter popular da maioria dessas residências. Pátina e "mentira estética" que remontam também, de modo ambíguo e instigante, ao pitoresco de Ruskin e ao princípio de revestimento de Loos. Essa enganosa e divertida ostentação nos faz lembrar a geometria da cidade patchwork, um sentido eclético para a prática da montagem, curiosamente tão contemporâneo, e também a dificuldade de se estabelecer, na arquitetura popular, onde começam e terminam cópia e criação, gratuidade e intenção, recreio e função. 

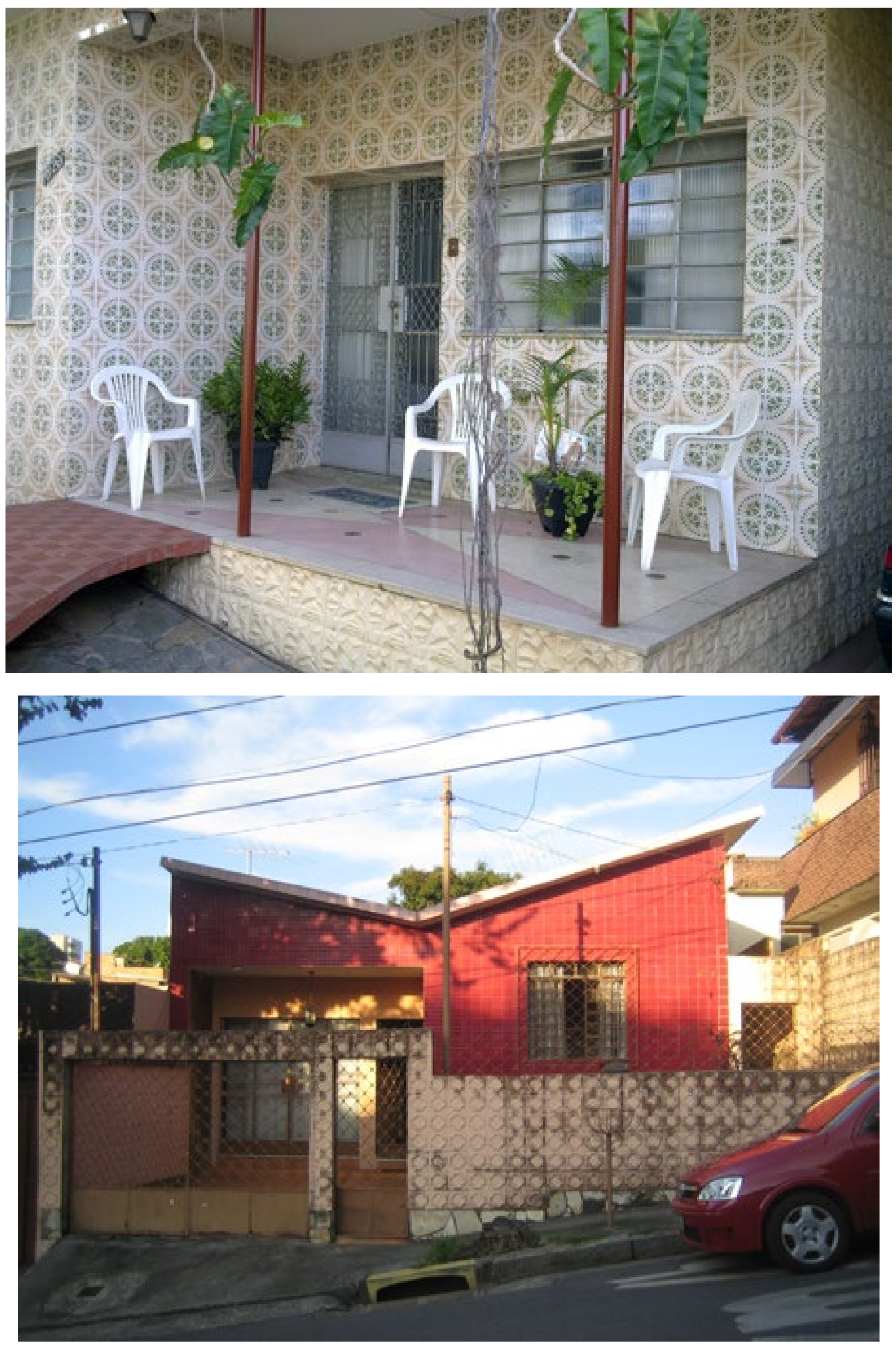

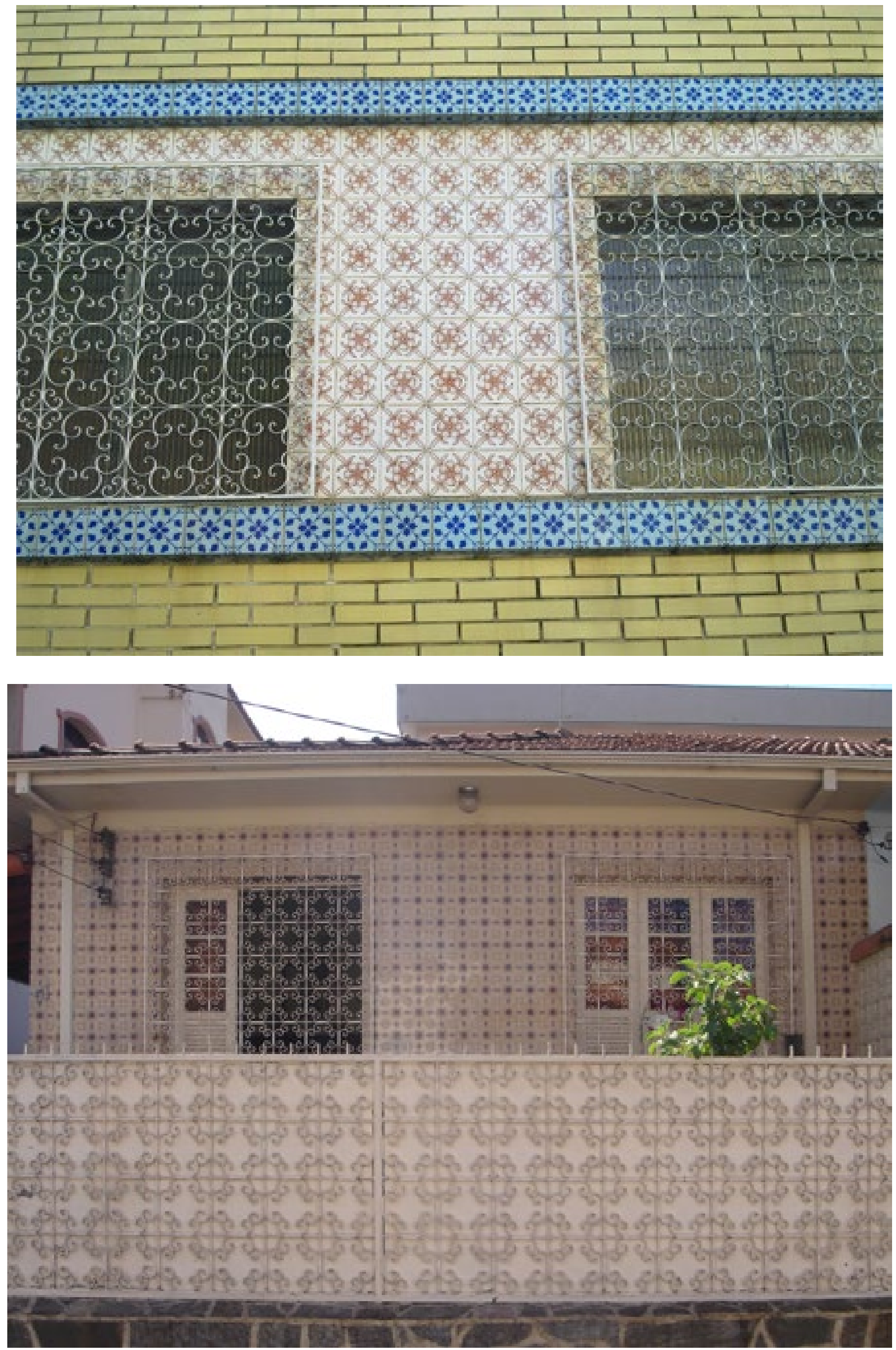

Fig. 4A, 4B, 4C e 4D. Casas patchwork. Fotos: divulgação Urbano Ornamento. 
A história das colchas leva a marca do nomadismo que interessa a Deleuze e Guattari (1995), expresso, como contam os autores, pelo frenesi da linha oriental que contamina a ocidental, e em seguida pelos colonos que deixaram a Europa em busca do Novo Mundo, e nele precisam aprender a trabalhar com o ordinário, com a falta, com os restos de tecido e os de baixa qualidade, os retalhos. Essas viagens marítimas também caracterizam a história do azulejo de fachada no Brasil, viagens de ida e de volta, herança portuguesa (interior, sagrada, e ainda árabe e ítalo-flamenga) adaptada às condições climáticas e criativas brasileiras, e apropriada, séculos mais tarde, na fachada exterior do colonizador. Cores e rendas para fora, a moradia se veste de azulejo, mas não mais os pintados à mão, que expressam narrativas religiosas e conquistas imperiais. Tal artesania dá lugar à industrialização e à seriação: superfície rendada que abandona o épico para voltar às suas origens orientais, o tapete na fachada (retirado da parede do interior árabe), naquele segundo quartel do século XIX. À máquina ou à mão, ainda assim, é preciso gostar de trabalhar com miudezas, forjar barra a barra, afixar cada azulejo, com a paciência do artesão. Retalhos ao sabor das disponibilidades e necessidades, o rendado exterior viria a firmar-se com sabor francês - fruto da "missão artística" que por essas terras se instalara -, na linguagem estética e técnica do eclético século XIX, sobretudo nos estados do Nordeste, especialmente o Maranhão. A despeito da tendência, nem tão passageira e muito contagiante, foi quase um século depois que o azulejo voltou a ser "moda" em terras mineiras, a partir do resgate moderno, especialmente com o conjunto da Pampulha. Cor, conforto e nacionalidade traduzem uma energia tropical, inaugurada pelo neocolonial e cristalizada pela singularidade de nosso modernismo (periférico, como essas casas). Há uma quase unanimidade em reafirmar os motivos que mantiveram o azulejo nas casas nordestinas: durabilidade e conforto térmico, ou seja, não demandar repintura e refrescar a casa. Nas colchas de que aqui tratamos, sobrepõem-se aos blocos de azulejos um quilte ${ }^{1}$ de linhas de ferro que une suas peças, não ao modo de rejunte, mas em uma unidade diversa, provocada pelas superfícies lineares - xadrez, zigue-zague ou sinuosos acabamentos - ao sobrepor seu conjunto.

Preservado o alinhamento da rua nos casarões antigos que aderiram ao azulejo na fachada, o século XIX trouxe também muito ferro ornamentado aos exteriores das habitações, pré-existentes ou em construção, grades que participaram das novas distribuições espaciais à moda eclética francesa. Ouro Preto substitui seus guarda- corpos de madeira por ferro fundido, os palacetes da Praça da Liberdade ganharam seus grandes portais e as casas-tipo, não muito diferentes de tantas outras espalhadas pelo Brasil, nessa época já eram projetadas com grades e gradis, cercando jardins e varandas que agora faziam parte da fisionomia urbana. Desde então, essa presença ornamental se somou à azulejar, nas tantas casas populares que adeririam ao modismo moderno, sobrepondo à nova arquitetura cores, volutas e a trivialidade dos banheiros e cozinhas. Domesticidade e feminilidade - com a estética da renda elevada ao quadrado, e dentro, triplicada, com papéis de parede e outros azulejos de diversas cores e combinações nas cozinhas e nos banheiros - marcam e associam

1 Nas colchas patchwork, o quilte é a costura, livre ou reta, que se sobrepõe aos blocos já costurados para manter as camadas firmemente unidas e criar um segundo nível de desenhos. 
a história de todas essas casas, numa mistura de certo modo anacrônica, juntando culturas, estilos, gêneros e classes.

\section{Colcha imaginária}

Ao final da tese, a conversa entre grades e ornamentos se somou à outra, sobre a memória e a vida daquelas casas antigas, que pareciam prontas a despedir-se. Uma conversa que permitisse conciliar memória crítica e afetiva, e que se contaminasse não apenas pelo acadêmico, mas pelo comum. Enxergar e costurar jardins onde houvesse invisibilidades. Costurar semelhanças e diferenças, fazer da ideia de vizinhança um resgate, tecer colchas imaginárias. Aprender junto e apostar em nascentes definições, vindas da boca de quem não está acostumado a falar sobre ornamentos, apenas a percebê-los. E, através deles, falar também sobre o bairro, a cidade, o patrimônio, a memória, o sacrifício, o desapego, a imensidão, as samambaias, as bijuterias e as jóias, a infância, a vida doméstica, a vizinhança, a família, a morte, a necessidade de mudança e de jardins.

Travessões atemporais e, de certo modo, ficcionais, se acreditamos com Cristina Freire (1998) que a cidade que habitamos é, como sua memória, imaginada. Uma tentativa de reconstituir - de modo fragmentado, mas não menos potente - uma certa memória do habitar, as casas e a cidade, a partir do relato de relatos, singulares e universais. "Recordar, em seu sentido etimológico, significa colocar de novo no coração, e a memória se constrói, literalmente, de maneira afetiva", atesta Freire (1998, p. 126). Um gesto de reterritorialização - já que no inventário os modelos de ornamento perdem o lugar geográfico de onde vieram - que permitiu à pesquisa ressituar-se na cidade a partir de outros olhares, contrapostos e justapostos aos meus e aos dos autores que coloquei em contato. As entrevistas promoveram uma escuta das "trajetórias normais" a que se refere Heliana Salgueiro, pois para a autora "a cidade está contida e fragmentada na globalidade desses nomes" (SALGUEIRO, 1997, p. 13), nessas histórias de parentesco e transmissão de saberes, que suscitam uma "grande diversidade de leituras, um movimento que parte da micro-história às macrorrealidades" (SALGUEIRO, 1997, p. 14). São constelações de sentido que esses depoimentos, costurados como em uma colcha patchwork, puderam oferecer, eficientemente reluzentes em sua aparente totalidade, para nos ajudar a entender em que medida o ornamento hoje vive (se viver for um estado mais vibrante do que sobreviver), no espaço urbano. Para o historiador Michel de Certeau (apud CHACHAM, 1994), as pequenas narrativas urbanas, de "profundidade desconhecida" e dimensão mítica, são capazes de criar outras dimensões, a partir de vocabulários conhecidos. Memória urbana como um antimuseu, como afirmou Cristina Freire, também a partir do historiador francês.

Portanto talvez seja aqui o lugar da dobra: sabores domésticos que migram para o espaço público, ornamento que sai de dentro para fora, não apenas como signo da ostentação que marcou a consolidação da classe burguesa no século XIX, mas também uma espécie de avesso, cuja viragem se dá pela dimensão do popular. Avesso de certo modo malquisto pela cultura moderna, mas que também podemos interpretar 
a partir dos valores de cuidado e intimidade, que vinculam de maneira inevitável, ainda que não exclusiva, ornamento e feminilidade. A restrição da paleta disponível (ou dos recursos para utilizá-la) leva o azulejo da cozinha para a fachada (o popular) e termina por escancarar no espaço público inegável domesticidade. Valores transformados, a partir e a despeito de suas motivações iniciais. E foi em 28 das 33 entrevistas que nos sentamos à varanda com mulheres, já que a maioria dos homens, vivos ou mortos, não habita mais essas casas.
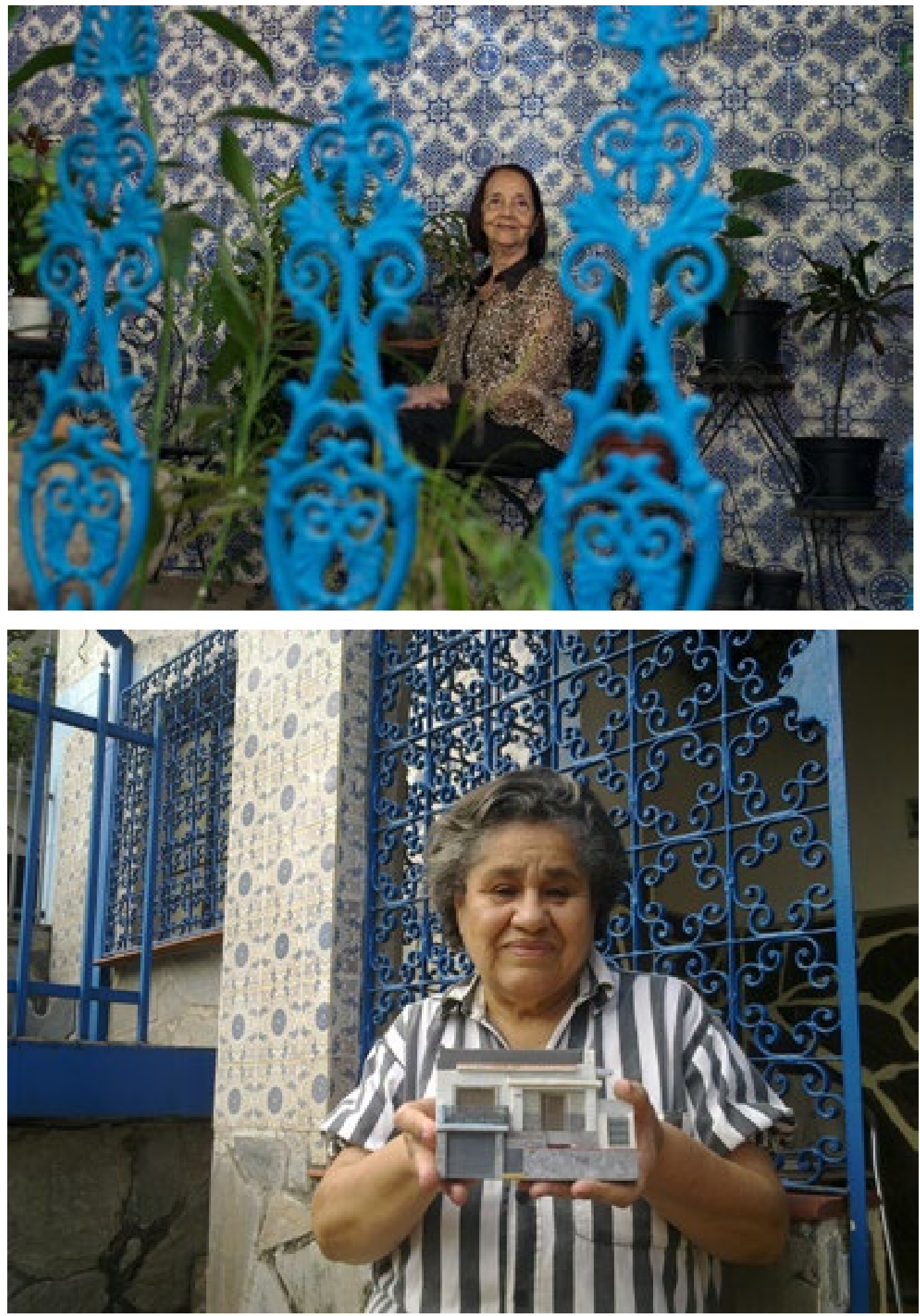

Fig. 5A e 5B. Moradoras das casas patchwork. Fotos: Alexandre Rezende. 
A cientificidade da entrevista ficou em segundo plano diante dos esforços por se estabelecer confiança e intimidade, elementos necessários para tecer a colcha com algum sentido de coletividade. Mas logo no começo vivenciamos a recusa da entrevista, como dado que se alinha à função das grades na fachada. Desconfiança e medo do corpo, que não se aproxima para o convite, somados a algum desdém e sobretudo à negativa que pode estar vinculada aos tempos de velocidade, inversamente proporcional ao labor da forja ornamental. No entanto, para os que nos presentearam com meia ou uma hora de conversa, indiferença foi palavra existente, mas rara. Indiferença com a casa geralmente sobreposta à indiferença com o entrevistador, empatia da casa que é palavra esquecida por seus donos. Mas em sua maioria aquelas casas sabiam fazer jus à sua personalidade de "casa de vó", respeitar sua vocação de ponto de encontro, de sede e referência familiar. As conversas se transformaram em convites a perceber, embora a maioria não desconhecesse o valor de seu patrimônio guardado - com "apego", "sacrifício", "dificuldade" - e fizesse questão de escancarar o seu orgulho por ele.

A fachada da sua casa te lembra uma colcha de retalhos? O que significa uma colcha de retalhos para você? Artesanal, simples, misturada, antiquada, paciente, aconchegante, que "agasalha mais do que qualquer coisa chique". Umas mais discretas, outras menos. Marmotagem, carnaval. Costureira, interiorana, brega, mineira, rural. Belo Horizonte que ainda tem um ar rural, olhar para a casa e saber que mora gente idosa nela. Ouvir da colcha e afirmar as rendas estampadas nos azulejos e forjadas nas grades. Ser convidado a negar ou a aceitar, a refletir, de modo trivial, sobre a ausência de neutralidade estampada por suas casas na paisagem e sobre a relação entre seu próprio modo de existir socialmente e o da casa.

Costurar semelhanças e diferenças, fazer da ideia de vizinhança um resgate. Convidamos a imaginar o modo com que as casas conversam com o bairro e se vestem para a rua; a estabelecer os lugares em que se traduz a fronteira entre o público e o privado; a refletir sobre as noções de patrimônio, ornamento e beleza, a partir do exercício de defini-los, e aproveitar para pensar sobre a infância, a vida doméstica, a vizinhança, a família, a necessidade de mudança e de jardins, a morte. Verificar o gosto pela ideia da casa (e de tudo que ela carrega, invisivelmente) virar história na cidade de papel que é o livro Urbano Ornamento. Remontar a história da casa a partir da vida, vincular os episódios da vida às reformas sofridas pela casa... Não havia histórias relevantes a se contar sobre a casa que não estivessem vinculadas às suas próprias histórias. Nenhuma história poderia ter acontecido somente ali, e ao mesmo tempo todas só poderiam ter acontecido ali.

Na maioria proprietários e aposentados, as pessoas com quem conversamos se apresentaram como guardiões, orgulhosos, do patrimônio construído ou adquirido. Ainda que os prédios, porque se multiplicaram, sejam motivos de estranhamento na paisagem, é a casa quem se singulariza, quem mantém "conversa quase solitária", destoando da maioria das construções. Também nelas o ornamento é chave mestra, vinculando-se quase que invariavelmente à ideia do antigo e da memória deste. Azulejos e grades trazem recordações de tempos antigos, que não devem e não podem ser retirados, nem sempre por opção, mas em respeito aos que os puseram ali e já se 
foram. Preservar a casa da maneira que é, mantê-la como foi concebida, guardar a memória e a escolha dos antigos moradores. Ornamento, aceitação e saudade...

Para os que os preservam por desejo próprio, os ornamentos estão predominantemente vinculados à ideia de um passado mais bonito e mais feliz, a despeito dos problemas estruturais que uma casa velha pode trazer. Aqui se populariza e se diversifica a colcha de retalhos, com remendos em ladrilhos - já não mais encontrados no mercado ou com preços salgados nos chamados cemitérios de azulejos - e outras camadas de grades, em versões mais geométricas, menos ornamentadas, e também pontiagudas e farpadas, honrosa exceção aos poucos que se orgulham de sua resistência, mantendo as muretas baixas. Dificuldade de reposição e escassez de mão de obra especializada. Obrigação de manter o estilo, medo de fazer modificação na coisa antiga, de estrutura desconhecida.

Os moradores gostam de expressar seu cuidado com a casa, mesmo quando maltratada por dentro ou por fora. Por mais judiadas que estejam pelo tempo, há algo vivo ali. Gostam de mostrar e de apontar as mudanças e as reformas, e têm algum cuidado em justificá-las: a família cresce, a madeira apodrece, a grade é baixa. Expressa como cuidado e simplicidade, a beleza aparece como um valor atual, tantas vezes vinculada ao ornamento, no exercício de defini-lo. O ornamento, no entanto, desaparecia da definição de "beleza", esta "uma coisa que não precisa de tanto ornamento para ficar mais apresentável", algo mais inerente que aderente, ao modo de Alberti, como se nossos interlocutores soubessem claramente de sua máxima: o ornamento é "uma espécie de luz subsidiária da beleza e como que seu complemento" (ALBERTI, 2011, p. 378).

Beleza exterior do ornamento e do corpo relativizada pela beleza interior, relacionada à simplicidade e à natureza -lembrando novamente o arquiteto italiano e seu ódio à suntuosidade -, encontrada nos olhos de quem vê, mas também inquestionável e arrebatadora. Como a beleza, o ornamento está fora e dentro, estendido aos objetos e ao cuidado da casa. Jardim, plantas, samambaias, o ipê da calçada que "faz parte da casa", "a arrumação interna que também é ornamento", "manter a casa pintada, limpa, de cara nova", "uma maneira de organizar as coisas". Para Alberti (2011), uma vez mais, ornamentum é também o que dá honra e dignidade a alguém.

As casas vestem-se para rua, sim, mas volta e meia precisam de uma roupa nova: uma reforma aqui, outra ali. Casas ímpares, de roupa contrastante, mostram a idade do bairro e seus ares familiares, a despeito de sua transformação. Casa que se veste de azulejo português, "um pedacinho de Portugal para a rua". Casas se negam a ser vestidas de muro. Casas de roupa simples, "conservadora", que "não tem nada de extraordinário", que evidencia o caráter popular do bairro em que está inserida. Patrimônio, ainda assim, que insiste em figurar como valor intangível, ainda que, espontaneamente, poucos tenham atentado para a característica que, em suas moradias, poderia representar um legado cultural e estético para a coletividade.

Patrimônio, beleza, ornamento, casa, memória, sacrifício, desapego, imensidão, olhar, modos de viver e trazer vida. Nessas poucas dezenas de horas, ouvi menos do que esperava sobre grades e ornamentos, temas que rápida e urgentemente, por maior que fosse a condução, cederiam lugar à memória afetiva, às histórias de vida 
privada, à constatação da finitude das casas e da vida. Nada muito diferente do que se verifica quando o assunto é, para além da arquitetura e do patrimônio, o habitar, ornamentado em maior ou menor medida, com suas doses mais ou menos equilibradas de melancolia e esperança, de saudade e devir...

***

VERMELHA COMO ROSA

A princípio, Dona Lídia não quis conversar, achou que eu estava vendendo algo, me avisou lá de dentro que não tinha disponibilidade. Espontaneamente perguntei- lhe por que não, com curiosa e inocente indignação - fruto das inúmeras recusas da primeira semana de entrevistas -, totalmente despropositada para o momento científico. Creio que ela se comoveu com o meu solitário e suado "por quê", debaixo de um dia mais do que quente, e instantaneamente mudou de ideia, convidando-me para entrar em sua casa revestida de azulejos vermelhos e cercada pela mureta de ladrilhos rosa-salmão, já dominada pelo mofo. Havia outros, escondidos - o diversificado mosaico de azulejos no chão da área externa e os brancos com detalhes florais vermelhos -, compondo em pedra e azulejos a sala de visitas que fora garagem, reduzida porque os carros diminuíram de tamanho, enquanto a família cresceu.

Sentadas no sofá, ela me conta do orgulho da família pela construção da casa, e da decisão coletiva de não vendê-la, na ocasião da morte do pai. Porém, "se entrasse um dinheirão muito grande", ela derrubaria e construiria uma outra completamente diferente. "Não é uma casa funcional para os dias de hoje" - explica.

Lídia me pede desculpas por ter recusado a entrevista a princípio, e diz que gostaria de ter a casa registrada em livro como uma homenagem a seus pais. Me chama para conhecer o restante da casa e começa a mostrar sua cristaleira, a mesa de mármore, as rendas portuguesas que guarda, as fotografias de família, as obras da filha (que é "meio artista") e, ao fim do percurso, uma flor muito rara que ela cultiva no quintal.

Não quer ser fotografada, mas pede licença para vestir uma blusa branca de bolinhas pretas, que acredito combinar com a fachada de sua casa, quando ela posa para a foto que não me autorizou mostrar a ninguém. Permanece em meus segredos de campo o sorriso pintado de batom vermelho, a combinar com a casa e com o brio de ambas.

Foi feito com prazer? Podemos fazer ecoar a voz de Ruskin aqui? Deixemos o binômio racionalidade/intuição alimentar conceitos e palavras de ordem modernas - autenticidade, autoridade, autoria, autorreferenciação, consciência, ideal - para, talvez, verificar como podem permanecer intactos os sistemas significantes da vida cotidiana. Talvez não precisemos ir a Veneza para aprender com Ruskin a dar atenção à alma das ruas e das casas, aos pequenos detalhes, e a olhar para alguns fazeres ornamentais "como focos privilegiados de resistência ao desencantamento do mundo" (PAIM, 2000, p. 36). Se o monumento é a exceção, a casa é a "nota normal da vida cotidiana do cidadão, é como uma lápide epigráfica da sua ascendência e da 
sua história" (SEVERO apud PINHEIRO \& D'AGOSTINO, 2004, p. 124). No entanto, se o monumento é também uma referência, ou, como quer Cristina Freire (1997), "uma projeção de um certo sentido de tempo sobre o espaço", ele deve envolver os "tempos da experiência, através da memória individual e coletiva" (FREIRE, 1997, p. 118). Equivalente ao que expressa Lúcio Costa, rendido a uma certa verdade marginal da arquitetura colonial: "Vendo aquelas casas, aquelas igrejas, de surpresa em surpresa, a gente como que se encontra, fica contente, feliz, e se lembra de coisas esquecidas, de coisas que a gente nunca soube, mas que estavam dentro de nós, não sei" (COSTA apud PINHEIRO \& D'AGOSTINO, 2004, p. 125). Parece que essas "permanências subterrâneas", nas palavras de Stéphane Huchet (2004a, p. 62) - se levamos em consideração que a maioria das casas patchwork tem um traçado geométrico, moderno - não podem ser negadas, nem ao menos esquecidas pelas vanguardas, são uma espécie de fantasma, um assombro perene. Há algo irrestível em uma colcha de retalhos, certa vez li em um manual de costura patchwork.

\section{Referências}

ALBERTI, L. B.; ESPÍRITO SANTO, Arnaldo Monteiro do; KRÜGER, Mario Júlio Teixeira. Da arte edificatória. Lisboa: Fundação Calouste Gulbenkian, 2011.

CHACHAM, V.; DUTRA, E.R.F. A memória dos lugares em um tempo de demolições : a Rua da Bahia e o Bar do Ponto na Belo Horizonte das décadas de 30 e 40. 1994. 257 f., enc. : Dissertação (mestrado) - Universidade Federal de Minas Gerais, Departamento de Sociologia.

DEL NEGRO, C. Do Ornamento. Rio de Janeiro : Graf. da Universidade do Brasil, 1961.

DELEUZE, G.; GUATTARI, F.. Mil platôs: capitalismo e esquizofrenia. Rio de Janeiro: Ed. 34, 1995.

FREIRE, C. Além dos mapas: os monumentos no imaginário urbano contemporâneo. São Paulo: Annablume: FAPESP: SESC São Paulo, 1997.

GOMBRICH, E.H. El sentido del orden. Estudio sobre la psicología de las artes decorativas. London: Phaidon, 2010.

GUIMARAES, D.; CAVALCANTI, L.. Arquitetura kitsch suburbana e rural. Rio de Janeiro: Paz e Terra, 2006.

HUCHET, S. Horizonte tectônico e campo "plástico" - de Gottfried Semper ao Grupo Archigram - pequena genealogia fragmentária. In: MALARD, Maria Lúcia (org.). Cinco textos sobre arquitetura. Belo Horizonte: Editora UFMG, 2005. 
Paradigmas arquiteturais e seus devires (II): Eisenman, Tschumi e outros. In: Desígnio. Revista de arquitetura e urbanismo. Faculdade de Arquitetura e Urbanismo da Universidade de São Paulo, FAU/USP, no2, setembro de 2004, p. 115-130.

LE CORBUSIER. A arte decorativa. São Paulo: Martins Fontes, 1996.

PAIM, G. R. A beleza sob suspeita: o ornamento em Ruskin, Lloyd Wright, Loos, Le Corbusier e outros. Rio de Janeiro: Jorge Zahar Editor, 2000.

PATETTA, L. Considerações sobre o ecletismo na Europa. In: FABRIS, Annateresa (org.). Ecletismo na Arquitetura Brasileira. São Paulo: Nobel; Editora da Universidade de São Paulo: 1987.

PINHEIRO, M. L. B; D'AGOSTINO, M. H. A noção de pitoresco no debate cultural das primeiras décadas do século XX no Brasil. In: Desígnio. Revista de arquitetura e urbanismo. Faculdade de Arquitetura e Urbanismo da Universidade de São Paulo, FAU/ USP, no1, março de 2004. Pp. 119-127.

SALGUEIRO, H. A. O ecletismo em Minas Gerais: Belo Horizonte 1894-1930. In: FABRIS, Annateresa (org.). Ecletismo na Arquitetura Brasileira. São Paulo: Nobel; Editora da Universidade de São Paulo: 1987.

SMEETS, R. Signos, símbolos e ornamentos. Rio de Janeiro: Tecnoprint, 1982.

ZUMTHOR, P. Performance recepção leitura. São Paulo: Educ, 2000. 